\title{
A STUDY ABOUT THERMAL SIMULATION IN SOLIDWORKS IN THE CASE OF DIFFERENT GEOMETRY OF THE PROCESSED PIECES BY CUTTING
}

\author{
IONEL OLARU ${ }^{* 1}$, CIPRIAN OLARU $^{1}$ \\ I "Vasile Alecsandri" University of Bacau, Calea Marasesti 157, Bacau, 600115, Romania
}

\begin{abstract}
In practice, different cutting processes are encountered, each process having different characteristics. Due to the existing friction forces between the workpiece and the cutting tool, a significant amount of heat is generated. This amount of heat can be determined by experimental measurements. This paper aims to study the way in which the temperature is propagated in the workpiece, so that the phenomenon can be understood and determined how this excessive heat can be removed from the cutting area.
\end{abstract}

Keywords: thermal simulation, piece, cutting, tools

\section{INTRODUCTION}

Mechanical machining processes are various. This involves removing the extra material with special machining tools. During the removal of the workpiece, some friction zones are generated between the tool and the workpiece. This friction in turn generates heat. Now there is an interdependence between the material chosen, the processing regimes and the heat generated by the cutting: the cutting movements, the tools used, the machining tools on which the machining is done. The shape of the chips is an indicator of the cutting process, showing the degree of plastic deformation suffered by the detached material layer, we can distinguish two types of chips: breaking and plastic deformation [1].

In machining by milling, the cutting process is accomplished by composing two movements: the main movement, the tool's rotation and the secondary movement, the advance of the piece caught in the device on the table of the machine-tools. By milling process may be made: the planar surfaces, conical, bore, wedge or helical channels, gears, etc. The bending speed on cutting is in the order of tens and hundreds of meters per minute, the temperature in the cutting area is very high and variable and the degree of deformation is high [2].

If we study these phenomena, it is easy to see that we have a conductive heat transfer in the workpiece. Thermal conduction involves the transmission of heat from close to closer to the particles of the same body, the particles that are in contact. Thus the heat is transmitted in the mass of material from the cutting area where the highest temperature is recorded. This heat passage takes place as a result of the difference in thermometric potential [3].

From the literature it is known that thermal transfer between two environments takes place in three ways: conduction convection and radiation. Conductive thermal transfer is characteristic of solid environments because it implies a particle immobility. Convective thermal transfer analogy is achieved between fluid and solid media (eg. between the workpiece and the atmosphere), sometimes it can also be combined with a heat transfer through radiation [4].

\footnotetext{
*Corresponding author, email: ionelo@ub.ro

(c) 2019 Alma Mater Publishing House
} 
By studying the different geometry of parts as well as several types of materials by computer simulation of thermal phenomena, which occur during the cutting process, can be made an optimization. Excessive temperature of some areas during cutting may be due to imperfections in making the cutting surface. The temperature can also be reduced by choosing an efficient cooling system for the processed area once the critical areas have been established [5].

\section{SIMULATIONS SETUP}

As we have established from the beginning, we have a heat dissipation through conduction in the mass of metallic material. If we analyze the Fourier law (Equation. (1)), we will know that the density of the heat flux is proportional to the temperature drop, or inversely proportional to the temperature gradient [6].

$$
q=-\lambda \operatorname{grad} t\left[\mathrm{~W} / \mathrm{m}^{2} ; \mathrm{kcal} / \mathrm{m}^{2} \cdot \mathrm{h} \cdot \operatorname{grad}\right]
$$

where $\lambda$ is the thermal conductivity $[\mathrm{W} / \mathrm{m} \cdot \mathrm{grad} ; \mathrm{kcal} / \mathrm{m} \cdot \mathrm{h} \cdot \mathrm{grad}], t$ is the temperature field that is based on the point considered and time.

In the case of a homogeneous piece, like the workpiece considered, the heat conduction is given by (Equation (2)):

$$
q=\frac{t_{2}-t_{1}}{R}\left[\mathrm{~W} / \mathrm{m}^{2}\right]
$$

where $t_{1}$ is the temperature in the processing area, $t_{2}$ is the temperature of the part before machining, and $R$ is the thermal resistance (Equation (3)) and is given by:

$$
R=\frac{\delta}{\lambda}\left[\mathrm{W} / \mathrm{m}^{2}\right]
$$

where $\delta$ is the length of the workpiece.

The working piece chosen to be studied and machined by milling has the following geometric elements, as can be seen in Figure 1. The geometry is simple: with a part with chamfer, another part with fillet and a hole.
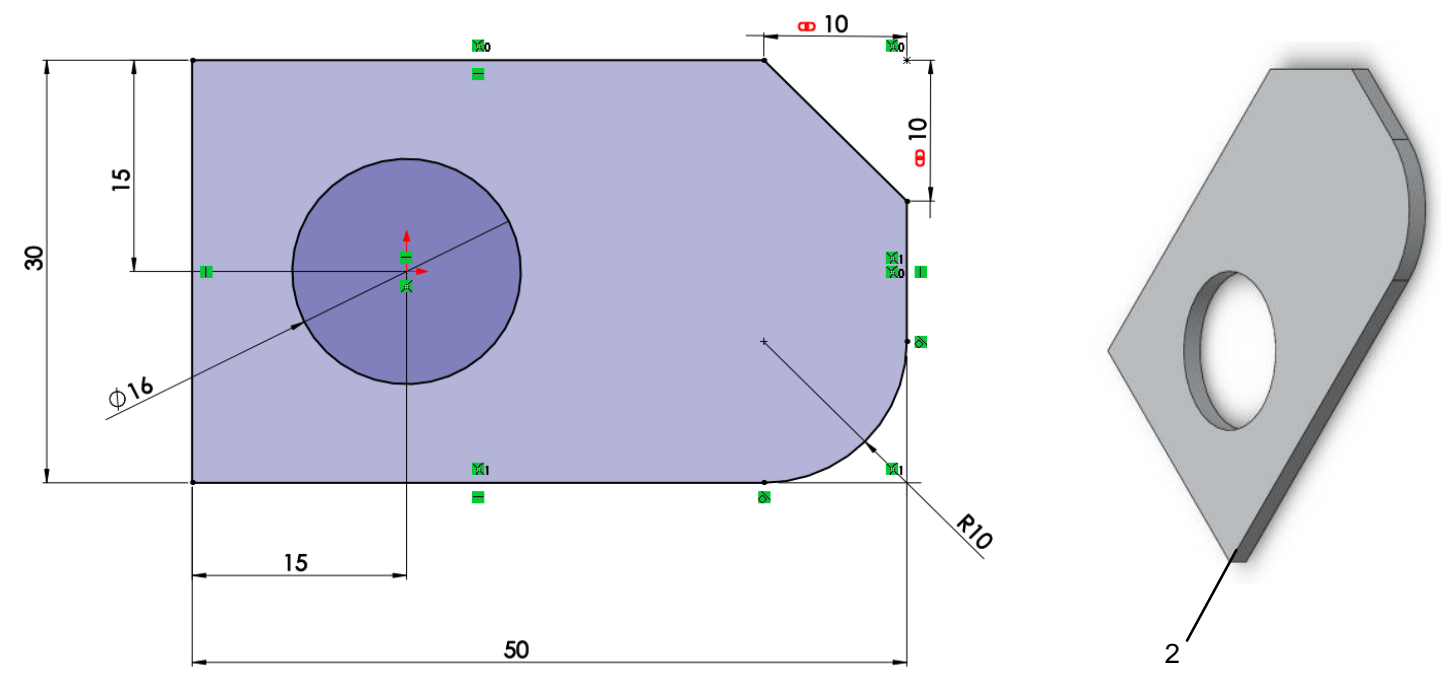

Fig. 1. The reference geometry of the aluminum alloy workpiece.

The workpiece is made from aluminum alloy, type AA6016-T4, the chemical compositions for this material is presented in Table 1. Initially, the piece has a rectangular shape, it will first process the chamfer, then the fillet 
area, and at the end the hole will be made. From a thermal simulation point of view, the material has the following thermal properties: thermal expansion coefficient $2.4 \mathrm{e}-005 / \mathrm{K}$, thermal conductivity $200 \mathrm{~W} / \mathrm{m} \cdot \mathrm{K}$ and specific heat $900 \mathrm{~J} / \mathrm{kg} \cdot \mathrm{K}$.

Table 1. Chemical composition (\%) of aluminum alloy, type AA6016-T4.

\begin{tabular}{|l|l|l|l|l|l|l|l|l|l|}
\hline $\mathrm{Mg}$ & $\mathrm{Si}$ & $\mathrm{Fe}$ & $\mathrm{Cu}$ & $\mathrm{Cr}$ & $\mathrm{Ti}$ & $\mathrm{Mn}$ & $\mathrm{Zn}$ & Others & $\mathrm{Al}$ \\
\hline $0.25-0.6$ & $1.0-1.5$ & 0.5 & 0.2 & 0.10 & 0.15 & 0.20 & 0.20 & $\leq 0.15$ & Balanced \\
\hline
\end{tabular}

\section{RESULTS AND DISCUSSION}

Simple geometric elements have been chosen for this simulation, these elements being common to most of the machined parts. The way of working is the following: the CAD model was realized and then the SolidWorks 3D model of the chosen element was subjected for analysis. Within the program there is a simulation module of different practical situations, it was chosen to study the thermal load of that element [7]. In Figure 2 we have the case of the processing of two surfaces: one plane and another curved representing the hole in the element.

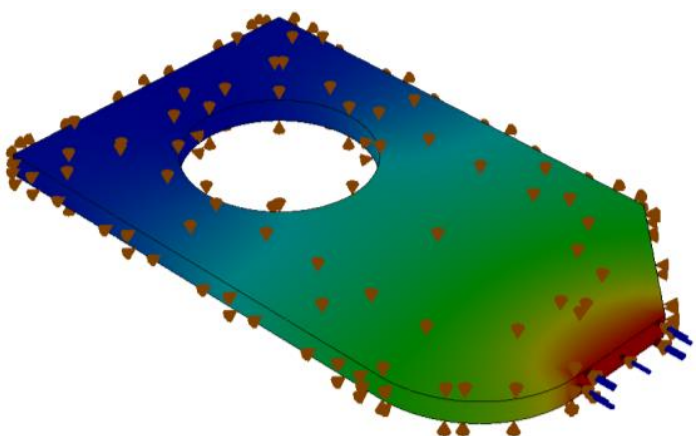

a.

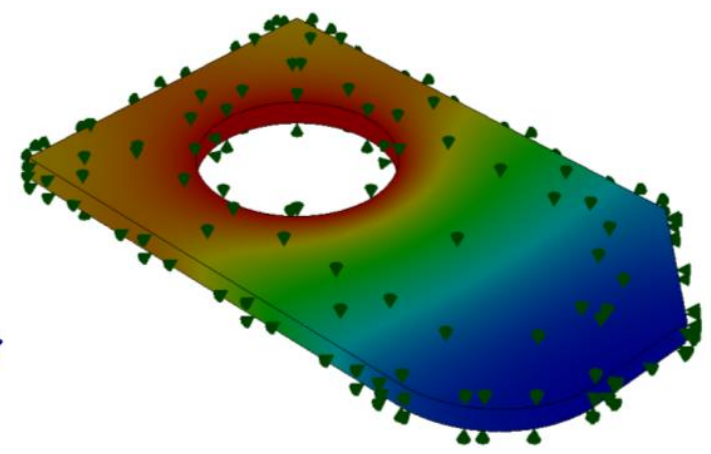

b.

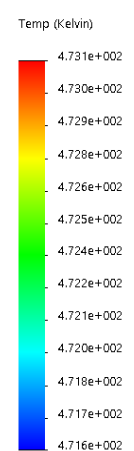

Fig. 2. Temperature distribution when processing a flat surface and a hole: a. flat surface; b. curved surface.

It is easy to see the temperature distribution in the mass of material. This is increased in the cutting area as it was and normally being diffused on a rather important area in the material mass. This first case is the simple case where a single operation of a single surface is performed.

In Figure 3 a composition of these two processing was analyzed, if they were carried out simultaneously, some influence on the temperature distribution was observed. In this case, practically there are no almost no part in the piece isn't uninfluenced by thermal machining.
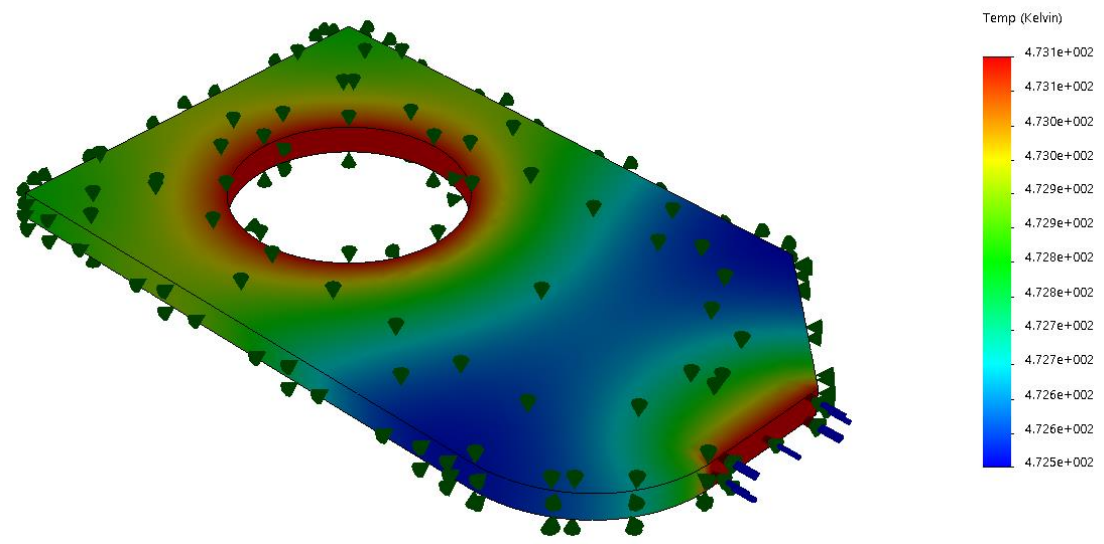

Fig. 3. Temperature distribution for simultaneous plane and hole processing.

In the initial part of the computer simulation, the material was chosen, namely aluminum alloy, type AA6016$\mathrm{T} 4$, with its own characteristics. When using other metallic materials, of course there will be differences in the temperature value of the simulations. In this case, an aluminum alloy sheet with a thickness of less than $2 \mathrm{~mm}$ is 
chosen, if the thickness or dimensions of the finished part are larger, we will certainly have another temperature distribution in the mass of the material.

In Figure 4 an export of a data for a long-term temperature distribution was performed for the main surface of the analyzed element. When these temperatures can be critical to the integrity of the material or other phenomena that are not welcome, it is possible to intervene in the critical areas by adopting efficient cooling systems, so that the temperature reaches normal values. This general temperature graph shows exactly where to intervene.

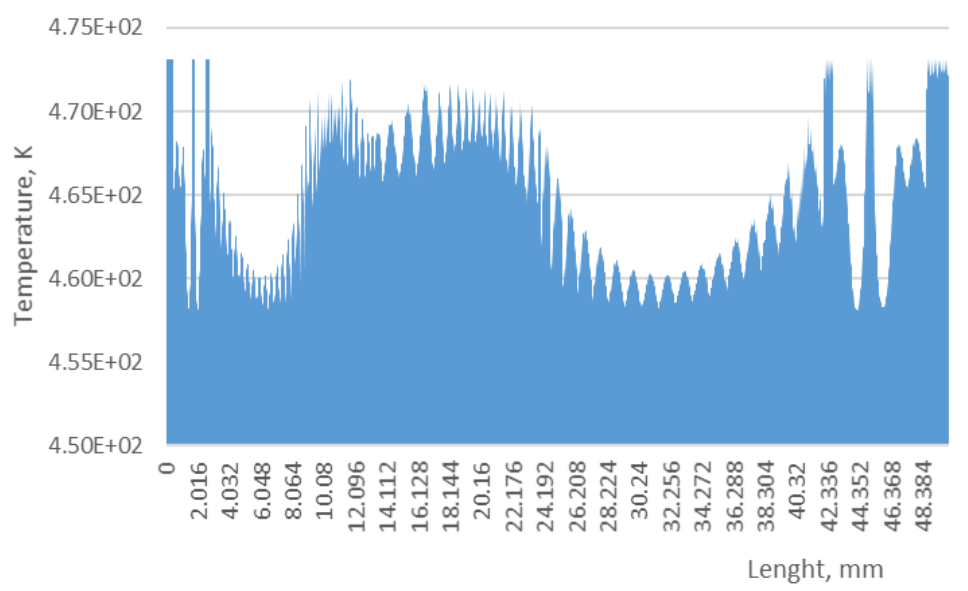

Fig. 4. The temperature distribution on the main surface of the workpiece.

As expected, areas where deformations or other imperfections may occur in the material are at the contact between the workpiece and the cutting tool. A temperature control in this area is given by the proper choice of material, cutting tool as well as the chosen work regimes.

\section{CONCLUSIONS}

A better knowledge of the phenomena that occur in the case of chip cutting helps to achieve the best processed elements. The excess heat in the cutting process can only be harmful. It has important repercussions in the newly created surface as well as creating in the material of residual tensions that cannot be accepted.

In many cases in the cutting process it is desired to remove this temperature from the cutting area, this is done by complex cooling systems which use from simple cooling water types, air to complex emulsions. Particular attention should be considered in the choice of materials to be processed and the processing regimes chosen.

By finite element simulation, the cutting parameters can be selected from the beginning, the geometry of the finite piece can be studied, what problems can arise through the realization of these surfaces and what would be the cutting temperatures and their propagation pattern. Not always by choosing a complex cooling system is beneficial, which can cause problems both in terms of costs, system and cooling fluids, and because of their impact on the environment. In contact with the cutting area of the aerosol is released may be harmful to the health of the operator.

\section{REFERENCES}

[1] Rowel, W.B., Morgan, M.N., Batakol, A., Jin, T, Energy and temperature analysis in grinding, transactions on engineering sciences, vol. 44, WIT Press, 2003.

[2] Zgorniak, P., Grdulska, A., Investigation of temperature distribution during milling process of Az91hp magnesium alloys, Mechanics and Mechanical Engineering, Technical University of Lodz, vol. 16, no. 1, 2012, p. 33-40.

[3] Rimpault, X., Workpiece subsurface temperature study during aluminum skin milling in slotting and ramping, ScienceDirect, Procedia CIRP 77, 2018, p. 417-420.

[4] Chang, H., Li, S., Shi, R., Design and manufacturing technology of high speed milling cutter for aluminum alloy, ScienceDirect, Procedia Engineering, vol. 174, 2017, p. 630-637. 
[5] Kesriklioglu, S., Pfefferkorn, F.E., Real time temperature measurement with embedded thin-film thermocouples in milling, ScienceDirect, Procedia CIRP, vol. 77, 2018, p. 618-621.

[6] Petre, M.V., Morega, A.M., Heat transfer by the side wall of an aluminum electrolysis cell, University Polytechnic Bucharest. Scientific Bulletin, Series C, vol. 72, no. 2, 2010.

[7] https://www.solidworks.com/partner-product/thermal-analysis-solidworks-simulation-2018 (10.02.2019). 